\title{
Influence of the angle of the bath bottom inclination in ergot isolation device on grain immersion in a liquid
}

\author{
Viktor Saitov ${ }^{1,2 *}$, Vyacheslav Farafonov ${ }^{2}$, Aleksey Saitov ${ }^{2}$ \\ ${ }^{1}$ Federal Agrarian Scientific Center of the North-East, 166 A, Lenin str., Kirov, 610007, Russia \\ ${ }^{2}$ Vyatka State Agricultural Academy, 133, October ave., Kirov, 610017, Russia
}

\begin{abstract}
For the mechanization of the allocation of toxic ergot from the rye seeds in a wet way, the urgent issue is the development of a device containing a bath with an aqueous solution of salt. The aim of the study is to determine the influence of the angle of inclination of the bottom of the bath on the rate of immersion of grains in the fluid of the device for separating ergot from rye seeds, which will ensure the efficiency of the process. Theoretically, we consider the movement of individual rye grains along the inclined surface of the bottom of the bath of the ergot extraction device. Rye grains have a density $\rho_{z}=(1.2 \ldots 1.5) 10^{3} \mathrm{~kg} / \mathrm{m}^{3}$, a length $l_{z}=(5.0 \ldots 10.0) 10^{-3} \mathrm{~m}, \mathrm{a}$ width $b=(1.4 \ldots 3.6) 10^{-3} \mathrm{~m}$, and a thickness $\delta=(1.2 \ldots 3.5) 10^{-3} \mathrm{~m}$. Geometric models of these grains are presented in the form of cylindrical and spheroidal grains. The movement of grain on the surface of the bottom of the bath of an ergot extraction device is considered at angles of inclination $\alpha=27,30,40,50,60,70,80$, and 90 degrees by the methods of mathematical modeling, classical mechanics using the laws of hydrodynamics. It was established that the angle $\alpha$ of the slope of the surface of the bottom of the bathtub to the horizontal should be taken at least $65^{\circ}$, at which accumulation is excluded due to the rapid rolling of the grain and a decrease in the thickness of its layer.
\end{abstract}

\section{Introduction}

The main raw material for the production of the most important food products for people and animal feed is the grain of the main cereal crops, such as rye, wheat, barley and oats. However, the listed main crops, especially winter rye, are often affected by ergot $[1,2]$.

Therefore, after threshing the grain mass with combine harvesters $[3,4,5]$, grain heaps contain poisonous ergot sclerotia in addition to grain, organic and mineral impurities $[6,7$, $8]$.

${ }^{*}$ Corresponding author: vicsait-valita@e-kirov.ru 
Therefore, to obtain grain suitable for food, technical and seed purposes, it is necessary to clean the grain heap, the task of which is to isolate all impurities, especially toxic ergot. The use of various and rather sophisticated grain cleaning machines does not give positive results when cleaning grain from these impurities due to the proximity of their physical and mechanical properties in terms of speed in the air flow and linear dimensions (width, thickness and length) [9-19].

However, the grains of the main grain crops (rye, wheat, barley and oats) have a larger specific gravity $\left(\rho_{z}=(1.2 \ldots 1.5) \cdot 10^{3} \mathrm{~kg} / \mathrm{m}^{3}\right)$ than ergot sclerotia $\left(\rho_{s}=(0.9 \ldots 1.15) \cdot 10^{3} \mathrm{~kg} / \mathrm{m}^{3}\right)$. Therefore, almost $100 \%$ purification of seeds from ergot sclerotia, which differ in density from grain, is possible in aqueous solutions of various inorganic salts [20].

This circumstance requires the creation of a less energy-intensive and more effective machine for the extraction of ergot sclerotia from the seed material, which has the most simple, convenient to set up and maintain the main working bodies [21].

One way to solve this issue is to create a machine for the separation of ergot sclerotia from grain, consisting of a bath, seed and waste conveyors (ergot sclerotia), a hopper with a feeder, the wall of which is immersed in a salt solution and separates the bath cavity with a seed withdrawal conveyor from the waste conveyor [22].

When developing such a machine and performing a technological process with the proper efficiency of ergot sclerotia extraction, studies are needed to justify the rational angle of the bath bottom between the seed and waste conveyors, which determines the speed of grain movement on the surface of this section of the bath bottom.

In this case, to obtain a more reliable picture of the process when the grains move in the fluid along an inclined plane, it is advisable to take into account the real linear dimensions and density of the grains, as well as the properties of the fluid, due to the appearance, in addition to the force $m_{z} g$ of gravity, the force $F_{t r}$ of sliding friction and the force $\mathrm{N}$ of the normal surface reaction, also forces $F_{\mathrm{A}}$ of Archimedes and forces $F_{\mathrm{C}}$ of fluid hydrodynamic resistance.

\section{Materials and methods}

Theoretically, we consider the movement of individual rye grains along the inclined surface of the bottom of the bath of the ergot extraction device. Rye grains have a density $\rho_{z}=$ $(1.2 \ldots 1.5) \cdot 10^{3} \mathrm{~kg} / \mathrm{m}^{3}$, a length $l_{z}=(5.0 \ldots 10.0) \cdot 10^{-3} \mathrm{~m}$, a width $b=(1.4 \ldots 3.6) \cdot 10^{-3} \mathrm{~m}$, and a thickness $\delta=(1.2 \ldots 3.5) \cdot 10^{-3} \mathrm{~m} \mathrm{[20] \text {. }}$

Geometric models of these grains are presented in the form of cylindrical and spheroidal grains. The movement of grain on the surface of the bottom of the bath of an ergot extraction device is considered at angles of inclination $\alpha=27,30,40,50,60,70,80$, and 90 degrees by the methods of mathematical modeling, classical mechanics using the laws of hydrodynamics.

\section{Results and Discussion}

The speed of movement of grain in a liquid is an important parameter when developing a machine for cleaning grain material by density in a wet way to justify its structural and technological parameters [23].

To determine this speed, it is necessary to take into account the geometric shapes of the grains, which have a great variety. Geometric shapes can mainly be represented as cylindrical and spheroidal grains. The scheme of forces acting on a cylindrical and spheroidal grains when immersed in liquids are shown in Figure 1 and in Figure 2.

When a cylindrical or spheroidal grain is dropped on the surface of the liquid and the 
surface tension is overcome, it will move at a constant speed. The grain will move in the liquid mainly flat due to the asymmetric location of the center of gravity in it. The grain is affected by gravity $m_{z} \vec{g}$, Archimedes force $\vec{F}_{\mathrm{A}}$, and hydrodynamic drag $\vec{F}_{\mathrm{C}}$. Then Newton's second law on the $y$ axis has the form:

$$
m_{z} g-F_{\mathrm{A}}-F_{\mathrm{C}}=0
$$

where $m_{z}$ - the weight of the grain, $\mathrm{kg}$;

$g$ - gravity acceleration, $g=9.81 \mathrm{~m} / \mathrm{s}^{2}$.

After analyzing the expression (1), the speed of immersion in a liquid was obtained for a cylindrical grain [23]:

$$
v_{z}=\sqrt{\frac{\pi r_{z} g\left(\rho_{z}-\rho_{z h}\right)}{2 c \rho_{z h}}},
$$

where $r_{z}$ - the radius of the cylindrical grain, $\mathrm{m}$;

$\rho_{z}$ - the density of the grain, $\mathrm{kg} / \mathrm{m}^{3}$;

$\rho_{z h}-$ fluid density, $\mathrm{kg} / \mathrm{m}^{3}$;

$c$ - the hydrodynamic drag coefficient, depending on the Reynolds number.

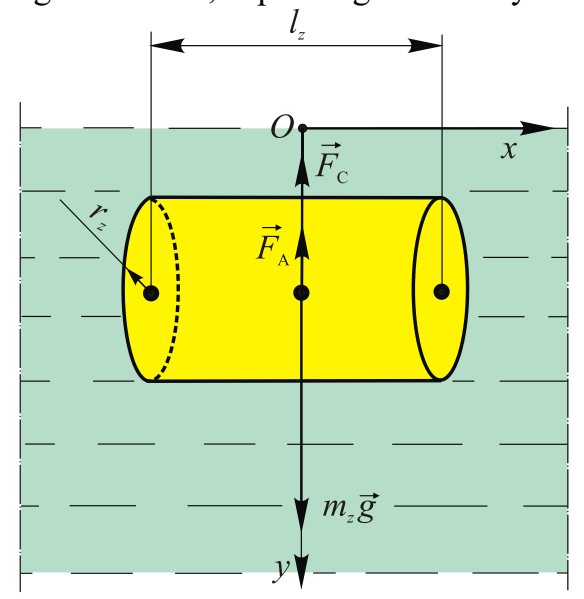

Fig. 1. The scheme of forces acting on a cylindrical grain when immersed in a liquid

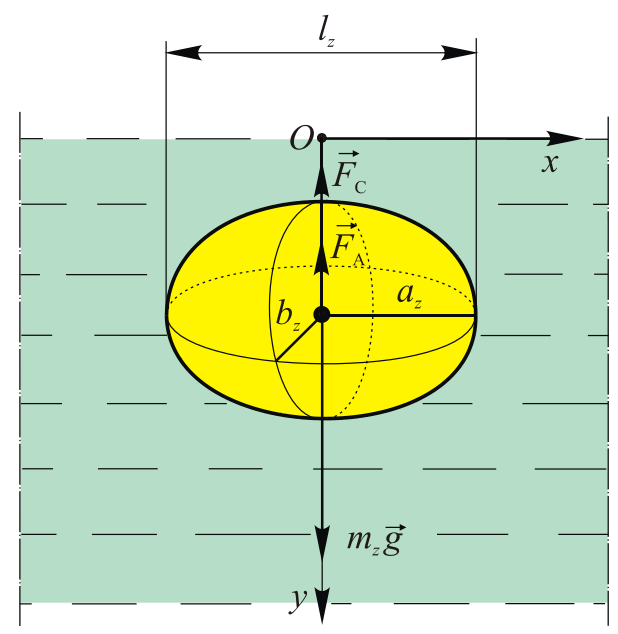

Fig. 2. The scheme of forces acting on a spheroidal grain when immersed in a liquid 
According to the scientific work [23] for a spheroidal grain, the rate of immersion in a liquid is expressed by the following equation:

$$
v_{z}=\sqrt{\frac{8 b_{z} g\left(\rho_{z}-\rho_{z h}\right)}{3 c \rho_{z h}}}
$$

Taking into account the parameters (width and thickness) of the rye grains under consideration and the assumption of the speed $v_{z}$ of the movement of the grain in the liquid $0.05 \ldots 0.10 \mathrm{~m} / \mathrm{s}$, the kinematic viscosity of the liquid $v=1.01 \cdot 10^{-6} \mathrm{~m}^{2} / \mathrm{s}$ (at a water temperature of $20^{\circ} \mathrm{C}$ ) the coefficient $c$ of hydrodynamic resistance for a cylindrical grain $c$ $=1.2$, and for a spheroidal grain $c=0.9[23,24]$.

After the grains are immersed in liquids, they enter the seed conveyor of the ergot extraction device, and part of the grains can reach the inclined surface of the bottom of the bath, located between the seed and waste conveyors, along which they begin to move.

The movement on this surface, as well as during immersion in the liquid due to the asymmetric arrangement of the center of gravity for the cylindrical grain will be characteristic along the diameter $2 r_{z}$ (flat), and for the spheroidal grain along the main minor axis $2 b_{z}$ (flat).

First, the grain will move slowly along the bottom surface depending on the angle $\alpha$ of inclination of the bottom surface to the horizontal and the initial speed of the grain on the bottom. At a small angle $\alpha$, the grain will slow down until it stops, and at large angles $\alpha$ slows down to a constant speed.

The scheme of forces acting on a cylindrical and spheroidal grains, moving along the inclined surface of the bottom of the bath with the liquid of the device for separating ergot from the grain, presented in Figure 3 and in Figure 4.

The basic equation for the dynamics of the movement of the grain in the liquid along the surface of the inclined wall of the bottom of the bath is written in the form:

$$
m_{z} \vec{g}+\vec{F}_{\mathrm{A}}+\vec{F}_{\mathrm{C}}+\vec{N}+\vec{F}_{t r}=m_{z} \vec{a}
$$

where $N$ - the reaction of the force of the normal pressure of the grain on the inclined surface of the bottom of the bath, N;

$F_{t r}$ - the friction force of the grain on the steel surface of the bottom of the bath, N;

$a$ - acceleration of the grain when moving along the inclined surface of the bottom of the bath with liquid, $\mathrm{m} / \mathrm{s}^{2}$.

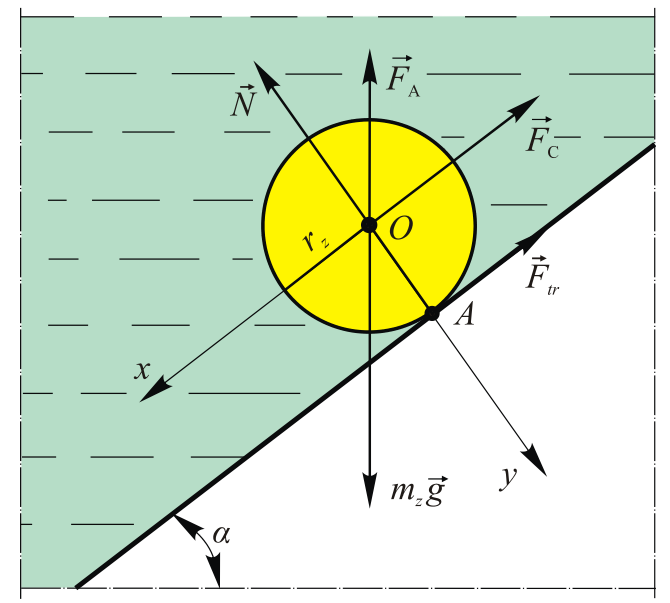

Fig. 3. The scheme of forces acting on a cylindrical grain, moving along the inclined surface of the bottom of the bath with the liquid of the device for separating ergot from the grain 
The reaction of the force $\vec{N}$ of the normal pressure of the grain on the inclined surface of the bottom of the bath is expressed:

$$
N=\left(m_{z}-m_{z h}\right) g \cos \alpha \text {. }
$$

The friction force when sliding the grain on the inclined surface of the bottom of the bath is expressed:

$$
F_{t r}=f \cdot N \text {, }
$$

where $f$ - the coefficient of friction of the grain against the inclined surface of the bottom of the bath.

Then equation (4) for a grain moving at a constant speed $(a=0)$, in projection on the inclined surface of the bottom of the bath (axis ox), taking into account the expressions (5) and (6), will have the form:

$$
m_{z} g \sin \alpha-m_{z h} g \sin \alpha-F_{\mathrm{C}}-f\left(m_{z}-m_{z h}\right) g \cos \alpha=0 \text {. }
$$

The mass of the cylindrical grain will be equal to [23]:

$$
m_{z}=V_{z} \rho_{z}=\pi r_{z}^{2} l_{z} \rho_{z}
$$

where $V_{z}$ - the volume of the grain, $\mathrm{m}^{3}$;

$l_{z}$ - the length of the grain, $\mathrm{m}$.

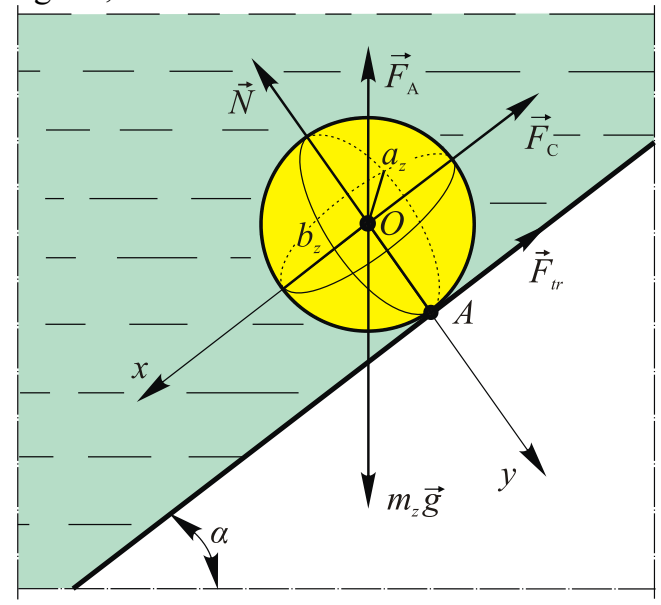

Fig. 4. The scheme of forces acting on a spheroidal grain, moving along the inclined surface of the bottom of the bath with the liquid of the device for separating ergot from the grain

The force $F_{\mathrm{A}}$ of Archimedes when immersed in a liquid cylindrical grain is equal to the weight of the liquid displaced by it [23]:

$$
F_{\mathrm{A}}=m_{z} g=V_{z} \rho_{z h} g=\pi r_{z}^{2} l_{z} \rho_{z h} g .
$$

The force $F_{C}$ of hydrodynamic resistance, acting from the liquid side on a cylindrical grain of length $l_{z}$, is expressed by the formula [23]:

$$
F_{\mathrm{C}}=2 c r_{z} l_{z} \rho_{z h} v_{z}^{2}
$$

For a cylindrical grain when moving along a diameter of $2 r_{z}$ (flat), equation (7), taking into account expressions (8), (9) and (10), is represented as:

$\pi r_{z}^{2} l_{z} \rho_{z} g \sin \alpha-\pi r_{z}^{2} l_{z} \rho_{z h} g \sin \alpha-2 c r_{z} l_{z} \rho_{z h} v^{2}-\pi f r_{z}^{2} l_{z}\left(\rho_{z}-\rho_{z h}\right) g \cos \alpha=0$.

Then the speed of the cylindrical grain when moving along the surface of the bottom perpendicular to the axis from the expression (11) is determined: 


$$
v_{z}=\sqrt{\frac{\pi r_{z} g\left(\rho_{z}-\rho_{z h}\right)(\sin \alpha-f \cos \alpha)}{2 c \rho_{z h}}}
$$

For a spheroidal grain, the force $F_{\mathrm{C}}$ of hydrodynamic resistance is determined by the following formula [23]:

$$
F_{\mathrm{C}}=\frac{c S \rho_{z h} v_{z}^{2}}{2},
$$

$S$ - the area of the projection of the body onto a plane perpendicular to the direction of movement of the grain (mid-section), $\mathrm{m}^{2}$.

When immersed in a liquid spheroidal grain along the main minor axis $2 b_{z}$ (flat), the area of the mid-section (spheroid) is equal to [23]:

$$
S=\pi b_{z} a_{z}
$$

where $a_{z}$ - the semimajor axis of the spheroid, $\mathrm{m}$.

The mass of the spheroidal grain will be equal to [23]:

$$
m_{z}=V_{z} \rho_{z}=\frac{4}{3} \pi b_{z}^{2} a_{z} \rho_{z} .
$$

The force of $F_{\mathrm{A}}$ Archimedes when moving in a liquid of a spheroidal grain is equal [23]:

$$
F_{\mathrm{A}}=V_{z} \rho_{z h} g=\frac{4}{3} \pi b_{z}^{2} a_{z} \rho_{z h} g .
$$

For a spheroidal grain, equation (7) in the projection onto the inclined plane of the bottom of the bathtub (axis $O x$ ) when moving along the main minor axis $2 b_{z}$ (flat) taking into account expressions (13), (14), (15) and (16) is represented as:

$$
\begin{aligned}
& \frac{4}{3} \pi b_{z}^{2} a_{z} \rho_{z} g \sin \alpha-4 / 3 \pi b_{z}^{2} a_{z} \rho_{z h} g \sin \alpha-\frac{\pi c b_{z} a_{z} \rho_{z h} \nu_{z}^{2}}{2}- \\
& -\frac{4}{3} \pi f b_{z}^{2} a_{z}\left(\rho_{z}-\rho_{z h}\right) g \cos \alpha=0
\end{aligned}
$$

Then the speed of the spheroidal grain when moving along the main minor axis $2 b_{z}$ (flat) along the surface of the bottom of the bath from equation (17) is equal to:

$$
v_{z}=\sqrt{\frac{8 b_{z} g\left(\rho_{z}-\rho_{z h}\right)(\sin \alpha-f \cos \alpha)}{3 c \rho_{z h}}}
$$

The speed of movement in the liquid along the inclined surface of the bottom of the bathtub of a cylindrical grain is lower in comparison with the speed of the spheroidal grain. This circumstance is due to the fact that the grains of the models under consideration differ in volumes and their hydrodynamic drags, for which, according to expressions (12) and (18), the coefficients $\sqrt{\pi r_{z} / 2 c}<\sqrt{8 b_{z} / 3 c}$.

If the grain lies motionless on the surface of the inclined bottom of the bath, then the force $F_{\mathrm{C}}$ of hydrodynamic resistance does not act. At the moment of the beginning of the movement of the grain along the surface of the inclined bottom of the bathtub, when еще $v_{z}$ $=0$, the friction force $\vec{F}_{t r}$ takes the maximum value as in equation (6). Then, from equation (7), the angle is expressed at which the moment of the beginning of the movement of the grain on the inclined bottom of the bath is determined:

$$
\alpha=\operatorname{arctg} f \text {. }
$$

Taking into account the coefficient $f$ of friction of rye against steel $0.3 \ldots 0.5$ the angle at which the grain begins to move along the surface of the bottom of the bath varies from 17 
to $27^{0}$.

To determine the effective angle $\alpha$ of the tilt of the bottom of the bath, which causes the rolling of the grains moving along it, it is necessary to determine the ratio of the speed of the grain along the surface of the tilt bottom of the bath to the speed of its free immersion in liquid from the angle $\alpha$ of the tilt of the bottom of the bath.

For a grain of the same model and the same physical and mechanical properties according to expressions (2), (3), (12) and (18), this ratio is (\%):

$$
P_{v_{z}}=\sqrt{(\sin \alpha-f \cos \alpha)} \cdot 100 \text {. }
$$

To calculate the speed of movement of the grain in the liquid along the inclined surface of the bottom of the bath, the highest value of the coefficient $f=0.5$ is taken to exclude cases of formation of arches that worsen the technological process of the ergot extraction machine from the rye grain.

The dependency graph (20) is shown in Figure 5, from which it follows that the ratio of velocities $P_{v_{z}}$ indicates a slowdown in the movement of grain along the surface of the inclined bottom of the bath with a decrease in the angle $\alpha$ of the slope of the bath bottom of the ergot extraction device.

For relatively small angles $\alpha=30 \ldots 50^{\circ}$, the value $P_{v_{z}}$ is $25.6 \ldots 66.7 \%$, respectively. At such small values $P_{v_{z}}$, the grain layer moving along the inclined surface of the bottom of the bath will be of considerable thickness. This will lead to the accumulation and arching of grain and the technological process of the ergot extraction machine from the grain will deteriorate. At angles $\alpha>60^{\circ}$, the value $P_{v_{z}}$ is more than $80 \%$, which indicates that accumulation is excluded due to rapid rolling of the grain and a reduction in the thickness of its layer.

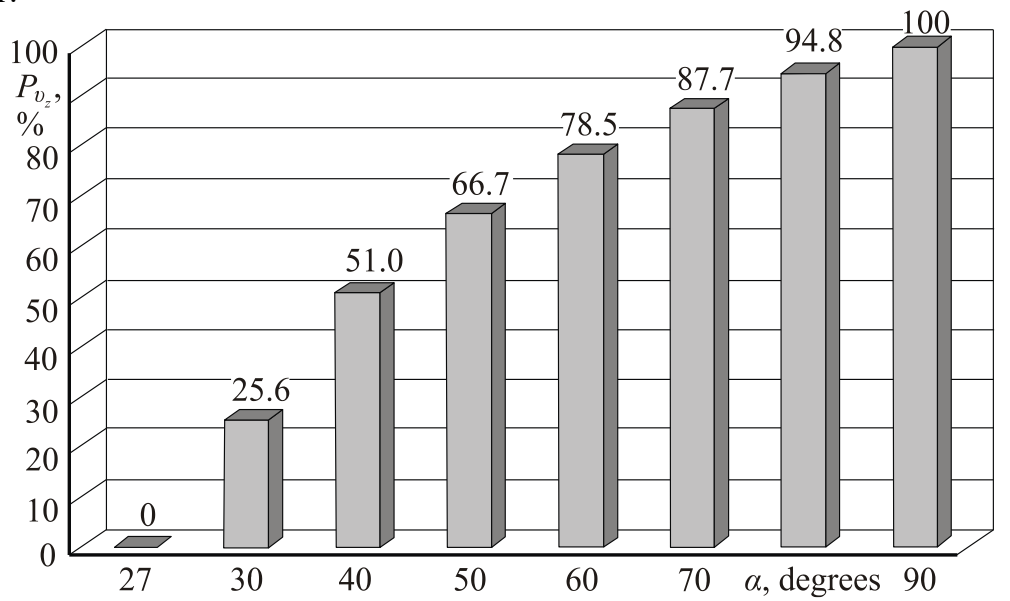

Fig.5. The dependence of the change in the ratio of the speed of movement of the grains along the surface of the inclined bottom of the bath to the speed of its free immersion in liquid from the angle $\alpha$ of the slope of the bottom of the bath of the ergot extraction device

For practical use, it is advisable to take the angle $\alpha$ of the bottom surface of the bath located between the seed and waste transporters at least $65^{\circ}$ in the ergot extraction machine, at which the value $P_{v_{z}}=84 \%$ indicates the elimination of vaulting due to rapid rolling of the grain and reducing the thickness of its layer [22]. 


\section{Conclusion}

Immersion in the liquid of individual rye grains with a density of $\rho_{z}=(1.2 \ldots 1.5) \cdot 10^{3} \mathrm{~kg} / \mathrm{m}^{3}$, a length $l_{z}=(5.0 \ldots 10.0) \cdot 10^{-3} \mathrm{~m}$, a width $b=(1.4 \ldots 3.6) \cdot 10^{-3} \mathrm{~m}$, a thickness $\delta=(1.2 \ldots 3.5) \cdot 10^{-}$ ${ }^{3} \mathrm{~m}$, and their movement along the inclined surface of the bath of the device for extracting ergot from the grain in a wet way with the proper efficiency of performing the technological process, the angle $\alpha$ of the slope of the surface of the bottom of the bath must be taken at least $65^{\circ}$. This value $P_{v_{z}}=0.84 \%$ indicates the elimination of vaulting due to rapid rolling of the grain and reducing the thickness of its layer.

\section{Acknowledgement}

The study was carried out according to the scientific theme "Creating a machine for the exclusion of poisonous impurities (ergot sclerotia) from winter rye grain by specific mass using aqueous solutions of inorganic salts" according to research work No. 0767-2019-0094 "Creating innovative technologies and new generation technologies for mechanization of crop production and animal husbandry, adapted to the climatic conditions of the North-East of the European part of Russia" under section 10.9, subsection 162 of the Program of fundamental scientific research of State Academies of Sciences for 2013-2020.

\section{References}

1. L.M. Schekleina, T.K. Sheshegova Teoreticheskaya i prikladnaya ehkologiya.1, 5-12 (2013). DOI: http://doi.org/10.25750/1995-4301-2013-1-005-012 (In Russ.)

2. T.K. Sheshegova, L.M. Schekleina, E.I. Utkina Agrarnaya nauka Yevro-SeveroVostoka 65(4), 30-35 (2018). DOI: https://doi.org/10.30766 / 20729081.2018.65.4.30-351 (In Russ.)

3. V.I. Orobinsky, A.M. Gievsky et al., Advances in Engineering Research. 870-874 (2018)

4. N. Aldoshin, O. Didmanidze Research in Agricultural Engineering.64(4) 209-214 (2018) DOI: http://doi.org/10.17221/107/2017-RAE

5. N. Aldoshin, O. Didmanidze et al., Engineering for Rural Development: Proceedings of 18th International Scientific Conference. 18, 100-104 (2019) DOI: http://doi.org/10.22616/ERDev2019.18.N110

6. L.M. Schekleina, T.K. Sheshegova Vestnik Mariyskogo gosudarstvennogo universiteta, 2(14), 83-90 (2018). DOI: https://doi.org/10.30914/2411-9687-2018-4-283-89

7. L.M. Schekleina Agrarnaya nauka Yevro-Severo-Vostoka, 20(2), 134-143 (2019). DOI: https://doi.org/10.30766/2072-9081.2019.20.2. 134-143 (In Russ.)

8. T.K. Sheshegova, L.M. Schekleina et al., Mikologiya i fitopatologiya, 53(3), 177-182 (2019) DOI: https://doi.org/10.1134 / S0026364819030127 (In Russ.)

9. V.I. Orobinsky, A.P. Tarasenko, et al., Advances in Engineering Research. 849-852 (2018) DOI: 10.2991/agrosmart-18.2018.159

10. I. Badretdinov, S. Mudarisov et al., Journal of Applied Engineering Science. 4(17), 529-534 (2019) DOI: https://doi.org/10.5937/jaes17-22640

11. A.M. Gievsky, V.A. Gulevsky, V.I. Orobinsky Vestnik Moskovskogo gosudarstvennogo agroinzhenernogo universiteta imeni V.P. Goryachkina, 3(85), 1216 (2018). DOI: https://doi.org/10.26897/1728-7936-2018-3-12-16 
12. P. Savinyh, Y. Sychugov et al., Engineering for Rural Development: 17th International Scientific Conference Engineering for Rural Development, Proceedings. 124-130 (2018). DOI: https://doi.org/10.22616/ERDev2018.17.N156

13. A.M. Gievsky, V.I. Orobinsky et al., IOP Conference Series: Materials Science and Engineering 327, $042035 \quad$ (2018). DOI: https://doi.org/10.1088/1757$899 X / 327 / 4 / 042035$

14. V.E. Saitov, R.F. Kurbanov, A.N. Suvorov. Procedia Engineering. 150, 107-110 (2016) DOI: https://doi.org/10.1016/j.proeng.2016.06.728

15. V.E. Saitov, V.G. Farafonov et al., IOP Conference Series: Materials Science and Engineering. 473, 012009 (2018). DOI: https://doi.org/10/1088/1757$\underline{899 X / 457 / 1 / 012009}$

16. V.L. Andreev IOP Conference Series: Materials Science and Engineering International Workshop «Advanced Technologies in Material Science, Mechanical and Automation Engineering». 32097 (2019). DOI: https://doi.org/10.1088/1757-899X/537/3/032097

17. V.I. Orobinsky, A.M. Gievsky et al., Vestnik Voronezhskogo gosudarstvennogo agrarnogo universiteta, 62(3), 13-18 (2019) DOI: https://doi.org/10.17238/issn2071$\underline{2243.2019 .3 .13}$

18. Yu.I. Ermoliev, A.A. Doroshenko, S.V. Belov, Vestnik Donskogo gosudarstvennogo tekhnicheskogo universiteta, 85(2), 59-68 (2016). DOI: https://doi.org/10.12737 / 19691

19. V.I. Orobinsky, A.M. Gievsky et al., Vestnik Voronezhskogo gosudarstvennogo agrarnogo universiteta, 61(2), 34-42 (2019) DOI: https://doi.org/10.17238/issn20712243.2019.2.34

20. V.E. Saitov, V.G. Farafonov, A.V. Saitov IOP Conference Series: Earth and Environmental Science. 341, 012123 (2019). DOI: https://doi.org/10.1088/1755$1315 / 341 / 1 / 012123$

21. K.D. Astanakulov, Y.Z. Karimov, G. Fozilov AMA, Agricultural Mechanization in Asia, Africa and Latin America. 42(4), 37-40 (2011)

22. A. Saitov, R. Gataullin, V. Saitov [A machine for separating ergot from rye seeds]. Patent RF, no. 2689470, 2019

23. V.E. Saitov, V.G. Farafonov, A.V. Saitov, Agrarnaya nauka Yevro-Severo-Vostoka, 20(4), 407-419 (2019), https://doi.org/10.30766/2072-9081.2019.20.4.407-419

24. V.A. Sysuev, V.E. Saitov et al., Russian Agricultural Sciences. 43(3), 273-276 (2017). DOI: https://doi.org/10.3103/S1068367417030156 